\title{
UNA APROXIMACIÓN INTERDISCIPLINAR AL CONCEPTO DE HUMOR
}

\author{
José Antonio Llera
}

Universidad de Extremadura

\section{INTRODUCCIÓN}

La peculiaridad etimológica de la palabra humor radica en una triple transición: si del restringido campo médico se aplica ya en la Edad Media a lo temperamental, a finales del siglo XVI, en Inglaterra, volvemos a encontrarnos con el término en un marco ya literario: el teatro de Ben Jonson. A partir de ese momento, su significado va a ensancharse o restringirse según los autores, países y épocas ${ }^{1}$. Para

\footnotetext{
${ }^{1}$ La observación que introduce Robert Escarpit (1962: 8) es muy pertinente: «Por un lado está la palabra que ha sido inventada o adoptada para designar, en cierto país, en cierta comunidad, un conjunto de experiencias vividas, de realidades individuales, cuya cohesión es esencialmente práctica. Por otro lado está la «cosa», es decir, el producto concluido de una reflexión que ha organizado lógicamente ciertas partes de la experiencia original y que luego ha generalizado el concepto así creado extendiéndolo a otras experiencias ajenas, pero que son semejantes».
} 
Hipócrates de Cos los humores corporales estaban vinculados a los cuatro elementos, y el temperamento humano venía dado por el predominio de uno de esos humores: sanguíneo (aire-sangre), flemático (agua-flema o pituita), bilioso (fuego-bilis amarilla) o melancólico (tierra-bilis negra o atrabilis). En el siglo II d. C., Galeno describe la enfermedad como un desequilibrio humoral; su Corpus Galenicum ejerce una influencia notable hasta que Paracelso pone en tela de juicio la teoría hipocrática. Paracelso quema simbólicamente, en 1526, los escritos de Galeno y proclama una medicina basada en la simbiosis entre el cuerpo y el alma (Escarpit, 1962: 14; Vilas, 1968: 17). De este vínculo entre lo fisiológico y lo temperamental da noticia el Diccionario Crítico Etimológico Castellano e Hispánico (s. v. húme$d o$ ): «del latín -umor, -oris, "líquido", "humores del cuerpo humano", pasa en la Edad Media al genio o condición de alguien, que se suponía causado por los humores vitales». Es en Inglaterra donde se fragua el tercer eslabón de la cadena fisiología-psicología-literatura, si bien la relación humor-literatura va a ser en principio puramente terminológica. La palabra humour es en Europa, entre finales del siglo XVI y mediados del XVII, una palabra ómnibus. Aprovechando la enorme popularidad alcanzada por el término, Ben Jonson acude a él para promocionar su doctrina de la comedia clásica. Ben Jonson lee con entusiasmo los Caracteres de Teofrasto, y a partir de la publicación en 1598 de Every Man in his Humour, piensa en utilizar la teoría de los humores para fundamentar un teatro de tipos ${ }^{2}$, a partir de las cuatro categorías básicas: el Colérico, el Atrabiliario, el Impulsivo y el Flemático. En todos los casos se trataba de personajes que eran víctimas patológicas de su temperamento (Escarpit, 1962: 16).

Parece justificado, pues, que la riqueza semántica del concepto humor sea la causa de un número de doctrinas y de opiniones tan abrumador desde la época clásica. Entre una bibliografía casi inabarcable hallamos enfoques desde ámbitos como la medicina, la antropología, la estética, la psicología, la sociología o la literatura ${ }^{3}$, si bien es cierto que bastantes hipótesis explicativas presentan conclusiones com-

\footnotetext{
2 «So in every human body, / the choler, melancholy, phlegm, and blood, / by reason that they flow continually / in some one part, and are not continent, / receive the name of humours. Now thus far / it may, by metaphor, apply itself / unto the general disposition: / as when some one peculiar quality / doth so possess a man, that it doth draw / all his affects, his spirits, and his powers, / in their confluctions, all to run one way, / this may be truly said to be a humour» (Jonson, s.d.: 62).

3 Para una revisión crítica de las poéticas humorísticas contemporáneas en español, puede verse J. A. Llera (2001).
} 
plementarias. Nuestra intención en las páginas que siguen es realizar una revisión crítica de las teorías más representativas, intentando agruparlas según las diferentes disciplinas que actúan en cada caso como centro imantador (cf. Arribas, 1997: 163-181; Johnson, 1976; KeithSpiegel: 1972; Milner, 1972; Raskin, 1985: 30-41).

\section{EL SUJETO QUE RÍE}

\subsection{Teorías de la superioridad}

Se centran en lo que tiene la risa de arrebato inmoral y arrogante, por lo que abordan el campo semántico del ridículo. Según Platón, al descubrir un vicio o una desgracia en el otro y reírnos de él sentimos un menosprecio burlón (Filebo, 48e-50d). En La República condena la risa por la pérdida de autocontrol que supone: «[...] no conviene que los guardianes sean gente pronta para reírse, ya que, por lo común, cuando alguien se abandona a una risa violenta, esto provoca a su vez una reacción violenta» (III, 388e).

En 1651 Hobbes publica Leviatán, su gran tratado sobre el poder absoluto. En sus páginas llama «gloria súbita» (sudden glory) a «la pasión que da lugar a esos gestos llamados RISA, y es causada o por algún súbito acto propio que complace, o por la aprehensión de algo deformado en un otro, por comparación con lo cual hay súbita autoaprobación» (1983: 163). El filósofo inglés da una vuelta de tuerca moral a la afirmación platónica al afirmar que «mucha risa ante los defectos de los otros es un signo de pusilanimidad. Pues una de las labores propias de las grandes mentes es ayudar y liberar a otros del desdén, y compararse a sí mismos solamente con los más capaces» (13). Resulta sintomático que Hobbes condenara radicalmente la risa. Tratándose de un fenómeno poderosamente ambiguo, que deconstruye la armonía estamental, que reconforta al sujeto consigo mismo y que incluso produce un enérgico e insobornable sentimiento de liberación no nos extraña la excomunión que le inflige.

A mediados del siglo XIX, Baudelaire no tiene dudas sobre la superioridad que manifiesta el fenómeno: «La risa viene de la idea de la propia superioridad. ¡Idea satánica como la que más! Orgullo y abe- 
rración» (1990: 23). Bajo el desconcierto que provoca, descubre su naturaleza satánica y humana, contradictoria ${ }^{4}$, ya que «a la vez es signo de una grandeza infinita y de una miseria infinita, miseria infinita respecto al Ser absoluto del que posee la concepción, grandeza absoluta respecto a los animales».

En 1899, Henri Bergson publica en la Revue de Paris uno de los ensayos más influyentes sobre la materia, Le rire. También él está convencido de que la risa, característica exclusivamente humana como ya había afirmado Aristóteles, es signo de superioridad: «El que ríe reentra en sí mismo y afirma más o menos orgullosamente su yo» (s. d.: 217).

La noción de superioridad también ha sido asociada con frecuencia a la ironía, si bien este tropo puede usarse de formas muy diversas. Según Kierkegaard, la ironía «mira por encima del hombro, por así decirlo, al habla normal y corriente que todos pueden entender de inmediato [...]. Se da principalmente en los círculos superiores» (citado por Booth, 1986: 58). Igualmente, para Schopenhauer, «la risa irónica advierte al adversario vencido cuán diferentes eran sus pensamientos con la realidad. Por eso el adjetivo ridículo es ofensivo» (1928: 173).

\subsection{Teorías psicoanalíticas}

El psicoanálisis insiste en los factores de ahorro, represión y liberación para explicar lo cómico: «El placer [...] de la comicidad (nos pareció surgir) de gasto de representación (de carga) ahorrado» (Freud, 1969: 215). Hay una diferencia de gasto psíquico que deviene superflua y se descarga. Desde el punto de vista fisiológico, Freud converge con las explicaciones anteriores de Spencer, para quien la risa sería una de las formas en que se canaliza la excitación del sistema nervioso: la energía psíquica excedente se convierte en el característico movimiento facial del que ríe. Freud entiende que lo cómico es una potencialidad; se descubre, no se inventa:

4 Comentando las ideas de Baudelaire, Octavio Paz hace hincapié en la ambiguiedad de la risa: «Expresión de nuestra distancia del mundo y de los hombres, la risa moderna es sobre todo la cifra de nuestra dualidad: si nos reímos de nosotros mismos es porque somos dos. Nuestra risa es negativa. No podía ser de otro modo, puesto que es una manifestación de la conciencia moderna, la conciencia escindida» (1972: 169). 
Lo cómico aparece primeramente como un involuntario hallazgo que hacemos en las personas; esto es, en sus movimientos, formas, actos y rasgos característicos, y probablemente al principio tan sólo en sus cualidades físicas, pero luego también en las morales y en aquello que éstas manifiestan (1969: 169).

Freud ejemplifica su teoría con un caso de comicidad situacional. Del análisis de la pantomima deduce que reímos de unos movimientos que tenemos por inútiles y desproporcionados en parangón con nuestros propios movimientos. Si en la pantomima la comicidad surge cuando el clown realiza un gasto mayor del que el sujeto que observa cree necesario, en el caso del disparate o la ingenuidad sucede a la inversa: «Tratándose de una función anímica lo cómico surge cuando la persona-objeto ahorra un gasto que consideramos indispensable, pues el desatino y la simpleza son rendimientos imperfectos» (1905: 175). Se trata en ambos casos de un vínculo polar: un contraste con respecto a un punto de referencia normativo o estereotipo cognitivo. En las últimas páginas de su estudio sobre el chiste, Freud se ocupa del humor como una de las clases de lo cómico; en concreto - estimala menos compleja, puesto que se realiza enteramente dentro del territorio de la subjetividad. En coherencia con su explicación de lo cómico y del chiste como mecanismos de economía psíquica, le atribuye un ahorro en el gasto de sentimiento. Para Freud, el humor supone el triunfo del yo y del principio de placer. El humor sería una especie de mecanismo de defensa que pone en marcha el individuo frente a las adversidades, intelectualizando el suceso:

Sólo considerando el desplazamiento humorístico como un proceso defensa podremos establecer algunas conclusiones sobre él. Los procesos de defensa son los que en lo psíquico corresponden a los reflejos de fuga, y su misión es la de evitar el nacimiento de displacer producido por fuentes internas. Constituyen, pues, una especie de regulación de la vida anímica (213).

Según Freud, el chiste tiene su fuente de placer en el ahorro del gasto de coerción o cohibición y, a diferencia de lo cómico, que se descubre, el chiste siempre se inventa (162). Matiza así sus distingos:

La participación de una tercera persona, a la que lo cómico es comunicado, intensifica el proceso cómico, pero no agrega a él nada nuevo. Por el contrario, el chiste precisa obligatoriamente de dicha tercera persona para la perfección del proceso aportador de placer (ibidem). 
El chiste es entonces inherente a su comunicación, y en tanto que nace para ser contado, diríamos que inaugura un proceso semiótico: «A la elaboración del chiste se halla indisolublemente ligado el impulso a comunicarlo, y este impulso es tan poderoso, que se impone con frecuencia, a despecho de importantes consideraciones» (126). Conceptualizado como desinhibición, Freud nos propone una taxonomía del chiste: el inocente, de carácter puramente estético; y el tendencioso, en el que ve un ingrediente sádico. Esta categoría se bifurca a su vez en hostil — vinculado a la agresión-y en obsceno. Las reflexiones de Freud tienen una profunda influencia en los estudios de Grotjahn (1957). Éste cataloga al ingenioso como un sádico que bajo el disfraz del juego y lo jocoso pretende destruir a su víctima. Por el contrario, el humorista es un masoquista pues se comporta como si conociera la miseria de este mundo, pero se decide a no tomarla en consideración [...]. No niega la existencia de la miseria, sino que pretende ser victorioso sobre ella. Es un ejemplo la esperanza de la victoria del narcisismo infantil sobre la experiencia. Su victoria es solamente parcial y pasajera; lo que puede ganar en fuerza interior y amabilidad lo pierde en el mundo de la realidad y la adaptación. Puede ser libre, pero no necesariamente feliz o bien adaptado a su ambiente (citado por Eidelberg, 1971: 217-218).

\subsection{Teorías estéticas}

La Introducción a la Estética (1804) de J. P. Richter representa la síntesis de las ideas románticas en torno al humorismo. Traducido al español por Julián de Vargas, en 1884, tendrá una influencia notable en bastantes teóricos y humoristas españoles (Llera, 2001). Las tesis de Richter pueden resumirse así:

1. Universalidad del humor. A diferencia del sentimiento de superioridad del satírico, para Richter la mirada humorística se caracteriza porque va dirigida hacia el mundo en general, lo cual explica su tolerancia para con los disparates de la humanidad. A partir de estos presupuestos, la reconciliación entre humor y sátira es imposible. El ojo del humorista siempre es panorámico, observa desde arriba; el del satírico singulariza su objeto. 
2. La idea aniquiladora o infinita del humor. «El humor, en oposición a la burla antigua, inspira sobre todo seriedad. Marcha sobre un borceguí, pero poco elevado, y lleva a menudo la máscara trágica, al menos en la mano» (1990: 98). De manera similar, la tradición inglesa había hablado de la burla pronunciada con un aire de tristeza.

3. Subjetividad del humor, como toda idea adjunta a lo romántico. El humorista se proyecta en todo lo que observa; de la conciencia de sí nace la parodia del yo, su carnavalización, su desdoblamiento: «Porque, consistiendo lo cómico en la destrucción del contraste que existe entre los dos principios, el subjetivo y el objetivo [...] no puedo imaginar ni poner este principio fuera de mí, sino que lo coloco en mí mismo, donde lo sustituyo con el principio subjetivo» (101).

3. Percepción del humor. Según Richter, el humor posee un ingrediente profundamente plástico y corporal; no se dirige al intelecto sino a los sentidos.

Hegel dedica una parte de su Estética al comentario de las ideas de Richter. El subjetivismo del humor tiene por efecto el desorden de todo valor objetivo y toda representación. «La representación —añade- no es ya sino un juego de la imaginación que combina a su agrado, altera y trastorna sus relaciones, un desenfreno del espíritu que se agita en todos los sentidos» (1928: 274). El filósofo idealista invoca a la autenticidad de la imaginación como fundamento del verdadero humor, «a fin de desarrollar lo que parece puramente arbitrario como realmente lleno de verdad» (276).

En 1898, Theodor Lipps publica Komik und Humor. Una buena síntesis de este ensayo la hallamos en sus Fundamentos de la Estética. Su teoría de lo cómico es de clara ascendencia kantiana: sorpresa e incongruencia. Describe el sentimiento de lo cómico como la fusión entre el displacer y el placer causado por la ruptura de nuestras expectativas sobre el acontecimiento en cuestión. De acuerdo con su hipótesis, existirían tres clases de comicidad: lo bufo, identificado con lo grosero; lo burlesco, asociado a la parodia; y por último lo grotesco, que es aquella comicidad presente en la caricatura, en la exageración y en algunas especies de lo monstruoso y lo fantástico (562-563). En una definición que se hará célebre, Lipps interpreta el humorismo como «el sentimiento de lo sublime en lo cómico y por lo cómico» (567). Lipps 
observa tres grados de humor: el humor humorístico (o reconciliado: versöhner Humor), el humor satírico, y el humor irónico. Se trata de tres maneras de ver el mundo. La primera se significa por su optimismo y su lirismo: «Me conduzco frente al mundo en el sentido estricto humorístico, cuando considero lo pequeño, lo mezquino, lo ridículo del mundo, pero me elevo sobre ello sonriente, conservo mi fe en ese mismo mundo» (569). El humor satírico se caracteriza por oponer a las contradicciones del mundo un ideal. Finalmente, hablamos de humor irónico cuando el sujeto es consciente del absurdo del mundo.

\section{EL SUJETO QUE RÍE EN SU CONTEXTO}

\subsection{Teorías antropológicas y sociológicas}

Algunos antropólogos han estudiado la risa a la luz de las teorías evolucionistas. Para ellos, la risa fue un factor coadyuvante a la adaptación de la especie; el que la risa sea un hecho universal incontestable induce a pensar que ha debido mantenerse con algún fin utilitario. Así, para McDougall (1922) la risa es un instinto portador de equilibrio ante situaciones extremas de abatimiento sin cuyo concurso la especie acaso no hubiera sobrevivido. Hayworth (1928) considera que la risa desempeñó funciones comunicativas en el periodo prelingüístico: era señal de buenas noticias e indicaba que el grupo podía relajarse, sin temer ningún peligro. Para antropólogos darwinianos como Ludovici (1932) o Rapp (1951) la risa es un primitivo vestigio del grito de victoria. El vencedor liberaba tras el esfuerzo del combate toda la tensión contenida; mientras que el vencido reequilibraba su tensión con el llanto. Según Rapp, la risa sufre lentamente un giro hacia lo intelectual: de la violencia originaria se pasaría al triunfo de la inteligencia capaz de elaborar y entender chistes o adivinanzas. Por ello Ludovici había utilizado el oxímoron al definir la risa como un «gruñido espiritualizado» (a spiritualized snarl).

Advertía Cicerón que no le importaban los aspectos fisiológicos de la risa, sino sus causas. El rendimiento retórico del humor consistiría en captar la benevolencia del auditorio, en confundir al adversario y sobre todo en atemperar los ánimos, deshaciendo lúdicamente una situación hostil: «odiosasque res saepe, quas argumentis dilui non 
facile est, ioco risuque dissolvit» (II, 236). Posteriormente, también Quintiliano llama la atención sobre los valores persuasivos del humor, en la medida en que actúa bloqueando la cólera: «odium iramque frequentissime frangat» (VI, 3, 9). Efectivamente: hay asuntos que se toleran mejor desde la óptica humorística. Recordemos que la figura del bufón de la corte gozaba de una licencia especial para bromear con personas de una jerarquía muy superior a la suya (Palmer, 1994: 30).

Para Henri Bergson, lo cómico expresa «cierta imperfección individual o colectiva que exige una corrección inmediata. Y esta corrección es la risa. La risa es, pues, cierto gesto social que subraya y reprime una distracción especial de los hombres y de los hechos» (s. d.: 102). Esa imperfección se hace patente en todo aquello que se aleja de la vida, de lo moral, de lo flexible: el automatismo, la rigidez del cuerpo o del espíritu. Antes que Freud, Bergson señala la agresividad de la risa: «A estas imperfecciones replica la sociedad con la risa, que es una impertinencia todavía mayor. La risa, entonces, no será muy benévola, pues pagará el mal con el mal» (212-213).

Freud sostiene que el chiste tendencioso cumple una función de válvula de escape de las pulsiones violentas del individuo, que se reconducen de esta forma a través del arma del ridículo. El chiste tendencioso representa la rebelión del individuo contra la censura social y la Razón. Como fuente de resistencia frente al superyó o cualquier agente represivo, el humor desarrolla una importante función crítico-catártica. Ahora bien, cabe objetar que si el chiste hace las funciones de mecanismo catártico que reemplaza a la violencia, puede entonces ser rentabilizado por el poder: permitiendo el chiste, se asegura en cierto modo que no se va a pasar a la acción directa. Sería pues erróneo concluir que el humor es un arma universalmente liberadora, puesto que tenemos suficientes datos como para afirmar que el humor también es utilizado por el discurso dominante para apuntalar su código de valores. El chiste como «pequeña revolución» (Orwell) no deja de ser una metáfora que se cumple sólo en la imaginación. Como en el carnaval, la liberación es transitoria y demuestra la existencia de una regla o ideología:

A diferencia de la fiesta oficial, el carnaval era el triunfo de una especie de liberación transitoria, más allá de la órbita de la concepción dominante, la abolición de las relaciones jerárquicas, privilegios, reglas, tabúes. Se oponía a toda perpetuación, a todo perfeccionamiento y reglamentación, apuntaba a un porvenir aún incompleto (Bajtín, 1974: 15). 
Los actores son los espectadores: todo el pueblo vive e inventa el carnaval. Se promueve el libre contacto entre iguales, en la plaza surge un lenguaje verbal y corporal desinhibido, que mezcla el juramento con la obscenidad. La risa, sea temporalmente, degrada, profana, disloca y posee un carácter ambivalente: «burlona y sarcástica, niega y afirma, amortaja y resucita a la vez» (1974: 17). El realismo de la comedia se vierte íntegramente en la representación carnavalesca hasta culminar en lo que Bajtín llama realismo grotesco, que ejemplifica la transferencia al nivel material o telúrico de todo lo espiritual y elevado.

Con unas tesis similares a las de M. Bajtín, Douglas —que no cita al formalista ruso- enfoca el problema del chiste a partir de conceptos como el de antiestructura o de antirritual (1968). Douglas considera que el chiste juega con una determinada estructura social y ve en este juego un reto, en la medida en que relativiza el estatus de dicha estructura: «The joke merely affords an opportunity for realizing that an accepted pattern has no necessity. Its excitement lies in the suggestion that any particular ordering of experience may be arbitrary and subjective» (365). Si el rito se significa por imprimir orden y jerarquía, el chiste subvierte las jerarquías y devalúa las normas dominantes:

From the physical to the personal, to the social to the cosmic, great rituals create unity of experience. They assert hierarchy and order. In doing so they affirm the value of the symbolic patterning of the universe [...]. But jokes have the opposite effect. They connect widely differing fields but the connection destroys hierarchy and order. They do not affirm the dominant values but denigrate and devalue. Essentially a joke is an antirite (369).

Sin embargo, esta teoría no explica el chiste inocente (Freud), aquél que surge lúdicamente, por mero placer intelectual, sin que se reproduzca en su forma ninguna estructura social análoga. Con todo, Douglas pone el énfasis en una cuestión que en el ensayo de Bajtín quedaba solamente implícita: al tratarse de una forma social, el chiste no representa una amenaza para la sociedad, es «una suspensión temporal de la estructura social» (372). Es decir, que la antiestructura aparece institucionalizada y regulada en el seno del plexo social como rito sobre la inversión de los valores, pero rito al fin. Umberto Eco insiste en esta apreciación: «En este sentido, la comedia y el carnaval no son modelos de auténticas transgresiones: por el contrario, representan ejemplos extremos del refuerzo de la ley. Nos recuerdan la existencia de la regla» (1984: 6). El semiótico italiano entiende el humor como una actitud filosófica ante la vida que, a diferencia del carnaval, no 
pretende llevarnos más allá de nuestros límites, sino que, más bien, nos dice cuáles son. Por ello se convierte en un verdadero movimiento de liberación: «El humor no nos promete liberación: por el contrario, nos advierte de la imposibilidad de una liberación global, recordándonos la presencia de una ley a la que ya no hay razón para obedecer. De esta forma socava la ley» (8).

Una de las aproximaciones más interesantes de los últimos años, desde el punto de vista sociológico, se la debemos a Michael Mulkay (1988). Según su propuesta, el humor se nutre de aquello que amenaza al discurso serio - la inconsistencia, la ambigüedad, la contradicción-, constituyendo una modalidad epistemológicamente superior: «In this important respect, humour seems to be supeior to ordinary, serious discourse, which is premised on an implicit denial of the fact that we live in a world of multiple meanings and multiple realities. It seems, therefore, that the serious mode is seroiusly defective» (219). De ello se deduce el potencial liberador del humor en relación con las ideologías, que dan una visión única del mundo para legitimar su poder y reglamentar la sumisión. Pero insistimos: el humor también puede ser utilizado para fortalecer sistemas de valores inmorales, e incluso deleznables.

Mulkay desarrolla en su investigación las ventajas del uso de la modalidad humorística para introducir un tema serio. Aunque el receptor puede extraer consecuencias serias de los enunciados humorísticos, el humor hace de barrera protectora, ya que «es una característica crucial del discurso marcado humorísticamente que cualquier intención o significado serios pueden negarse siempre» (Mulkay, 1988: 71; la trad. es mía).

\section{EL OBJETO RISIBLE}

\subsection{Teorías de la incongruencia}

Aristóteles se refiere en su Retórica (III, 1412a-1423) a la ruptura de expectativas con resultados humorísticos, y Cicerón sitúa a la decepta exspectatio entre los géneros del ridiculum: «Sed ex his omnibus nihil magis ridetur quam quod est praeter exspectationem» (II, 70, 284). 
Todo ello reaparece algo más desarrollado en la primera mitad del siglo XVIII, en el libro de Francis Hutcheson Reflections upon Laughter. Después de criticar las teorías de la superioridad arguyendo que la risa tiene causas múltiples, señala como método propicio «el contraste $u$ oposición de las ideas de dignidad y de bajeza» (citado por Arribas: 171), frase que nos parece próxima a la definición ciceroniana de aquella clase de chistes que se elaboraban comparando una cosa con otra más fea o más torpe (II, 289).

En el último cuarto del siglo XVIII, J. Beattie sostiene que la causa de la risa hay que buscarla en «an opposition of suitableness and unsuitableness, or of relation and the want of relation, united, in the same assemblage» (1776: 603). Pero es la teoría kantiana la que ha sido más influyente. En su Crítica del juicio, el filósofo de Könisberg sostiene que la risa es una emoción consubstancial a los sentidos, «que surge de la súbita transformación de una ansiosa espera en nada» (1977: 240). Según Kant, es un efecto de verosimilitud el que organiza dicha tensión y la mantiene hasta el final, en un proceso dinámico de ocultación y revelación. El humor sería una actitud muy representativa del espíritu en que la incongruencia guarda cierta lógica: «[...] todas las cosas son juzgadas de una manera totalmente distinta de la ordinaria (incluso al revés), y, sin embargo, conforme a ciertos principios de la razón, en semejante disposición de espíritu» (244). Recordemos también que Freud, al comentar las ideas de Richter sobre lo cómico, observa que el chiste consiste en encontrar «analogías entre lo disparejo; esto es, analogías ocultas» (1969: 9).

En 1819 Schopenhauer, que se jacta de haber resuelto el problema, considera que lo que define lo risible es una «inclusión paradójica» entre lo realmente experimentado y lo pensado, cosa que no ocurriría en el razonamiento lógico, en lo serio, donde concuerdan pensamiento y realidad. Schopenhaeur lo expone como una victoria de la experiencia sobre el pensamiento abstracto:

[...] la percepción de la incongruencia entre lo pensado y lo intuido, es decir, la realidad, nos causa alegría y nos entregamos gustosos al espasmo nervioso que este descubrimiento nos produce. La razón es la siguiente: en la contienda entre la intuición y el pensamiento, aquélla aparece siempre vencedora porque no está sujeta a error [...]. Si profundizamos en este análisis, veremos que el conflicto procede de que el pensamiento no puede abarcar todos los infinitos matices de la realidad. La victoria del conocimiento intuitivo sobre el pensamiento abstracto nos gusta, porque la intuición es la forma natural del conocimiento inseparable de la naturaleza animal (1928: 173). 
Ya a las puertas del siglo XX el autor más destacado en la línea de las teorías de la incongruencia es Bergson, quien sitúa las causas de lo cómico en la repetición, en la inversión y en lo que denominó interférence des séries: dos esferas del significado entran en colisión para alumbrar una tercera. Esta idea la recoge Koestler, a quien le interesa el chiste como prueba de la creatividad humana, capaz de pensar simultáneamente en dos esferas nocionales; es lo que denomina «biasociación» (bisociation):

[...] the perceiving of a situation or idea, $L$, in two self-consistent but habitually incompatible frames of reference, $M_{1}$ and $M 2$. The event $L$, in which the two intersect, is made to vibrate simultaneously on two different wavelengths, as it were. While this unusual situation lasts, $L$ is not merely linked to one associative context, but bisociated with two (1964: 35).

Como ya habían apuntado en sus teorías Hobbes o Kant, Koestler insiste en que esa biasociación debe ser imprevista (sudden), y que la descarga emocional debe estar presidida por un componente agresivo, en convergencia con la opinión de Freud. Inexplicablemente, estas teorías no se han relacionado con el mecanismo de los tropos y de la imagen asociada en general. Como en los tropos, la incongruencia humorística se produce a causa de una interacción entre dos esferas conceptuales.

Aunque autores del siglo anterior ya habían hablado sobre la existencia de un proceso de desconcierto-esclarecimiento (Dugas, 1902: 113) y de deslumbramiento-iluminación (Lipps, 1923: 556 y ss.), es sobre todo a partir de los años setenta cuando, desde la psicología cognitiva, algunos teóricos consideran que la incongruencia debe seguirse de una resolución para podamos hablar de humor (Shultz, 1972). A la ruptura de las expectativas le sucede el hallazgo de una regla que restaura lo incongruente, entendiendo por tal «una proposición lógica, una definición, o un acontecimiento de la experiencia» (Suls, 1972: 82) ${ }^{5}$. Desconfiamos, no obstante, de que este principio de la reconciliación sea aplicable a toda una inmensa variedad de chistes. Desde

5 Más recientemente, autores como Forabosco matizan estas teorías. Incongruencia y congruencia serían fenómenos yuxtapuestos y simultáneos: «The two-stage scheme may be supplemented in the following way: the subject perceives an incongruity; he identifies the cognitive rule; he perceives the aspect of congruency and, together with this, the incongruity, both new and/or initial [...]. There is therefore a succession (diachronicity) of incongruity-congruence configurations that terminates in a contemporaneous (synchronicity) of incongruity/congruence» (1992: 59-60). 
luego es una tesis que no funciona para dar cuenta de lo cómico inquietante de los románticos, para el humor grotesco o del absurdo. Por ejemplo, ¿cómo hallamos la regla cognitiva en este otro diálogo de Tono, de inequívoca herencia surrealista?:

— ¿Dónde habré puesto las gafas?

- Pero si la tienes en la nariz...

$\longrightarrow$ Sí, pero ¿dónde he puesto la nariz? (1949: 114)

\section{CONCLUSIONES}

a) En la medida en que estamos frente a un concepto complejo, se impone el estudio interdisciplinar, la perspectiva integradora.

b) Si bien las teorías antropológicas y de la superioridad ponen de relieve la agresividad aneja al humor, y las teorías estéticas provenientes del romanticismo alemán enfatizan su carácter reconciliado, es necesario aplicar una óptica pragmática (contextos de emisión y de recepción) menos simplista, que analice la práctica semiótica de un fenómeno que no obedece a una función predeterminada de antemano. El humor puede agredir buscando la complicidad con el receptor o simplemente constituirse en juego intrascendente; puede asociarse con los objetivos correctores de la sátira o consagrarse a un autotelismo «blanco».

c) Por la misma razón antes apuntada, y a despecho de ciertas teorías sociológicas o psicoanalíticas, el humor puede usarse tanto para liberarnos de la opresión como para robustecer el statu quo. Se trata de una modalidad permeable a mentalidades y códigos de valores contrapuestos; no puede hablarse con propiedad de una finalidad a priori, ajena a su enunciación. Asimismo, y como advertían los clásicos, el humor puede liberar la tensión y ser por ello muy persuasivo, pero también puede irritar profundamente al receptor, dependiendo de su ideología (por ejemplo, el chiste racista o la broma machista).

d) Del mismo modo que en los tropos, desde una perspectiva linguiística más sistemática podría decirse que el humor se basa en una yuxtaposición o contraste conceptual; o en la frase de 
Raskin (1985) ${ }^{6}$, en un contraste entre guiones (scripts), entre bloques de información semántico-pragmática.

\section{Referencias bibliográficas}

ARISTóteles (1990). Retórica. Ed. y traducción de Q. Racionero. Madrid: Gredos.

ARRIBAS, I. (1997). La literatura de humor en la España democrática. Madrid: Pliegos.

AtTARdo, S. (1994). Linguistic Theories of Humor. Berlín-Nueva York: Mouton de Gruyter.

BAJTín, M. M. (1974). La cultura popular en la Edad Media y Renacimiento. Barcelona: Seix Barral.

BAUdelaire, Ch. (1990). De la esencia de la risa y, en general, de lo cómico en las artes plásticas. Madrid: Visor.

Beattie, J. (1776). «Essay on Laughter and Ludicrous Composition». En Essays, 583-705. Edinburgh: William Creech.

Bergson, H. (s.d.). La risa. Ensayo sobre la significación de lo cómico. Valencia: Prometeo.

Booth, W. C. (1986). Retórica de la ironía. Madrid: Taurus.

CiCerón, M. T. (1976). De oratore. Ed. bilingüe latín-inglés de E. W. Sutton y H. Rackham. Cambridge: Heinemann y Harvard University Press.

Douglas, M. (1968). «The Social Control and Cognition: Some Factors in Joke Perception». Man 3, 361-376.

Dugas, L. (1902). Psychologie du rire. París: Félix Alcan.

Eco, U. (1984). «The Frames of Comic Freedom». En Th. A. Sebeok, (ed.), Carnival! 1-9. Berlín-Nueva York-Amsterdam: Mouton Publishers.

ESCARPIT, R. (1962). El humor. Buenos Aires: EUDEBA.

Forabosco, G. (1992). «Cognitive Aspects of the Humor Process: The Concept of Incongruity». Humor 5, 45-68.

FREUD, S. (1969). El chiste y su relación con lo inconsciente. Madrid: Alianza. HAYWORTH, (1928). «The Social Origin and Function of Laughter». Psychological Review 35, 367-385.

HobBES, Th. (1983). Leviatán. Madrid: Editora Nacional.

JoHnson, R. (1976). «Two Realms of a Joke: Bisociation Theories of Joking». Semiotica 16, 195-221.

Jonson, B. (s. d.). The Complete Plays of Ben Jonson, vol. I. Londres-Nueva York: J. M. Dent \& Sons y E. P. Dutton \& Co.

\footnotetext{
${ }^{6}$ Las teorías de Raskin tienen su continuación en los estudios de S. Attardo (1994).
} 
KanT, I. (1977). Crítica del juicio. Madrid: Espasa-Calpe.

KeItH SPIEgEL, P. (1972). «Early Concepcion on Humor: Varieties and Issues». En J. H. Goldstein y P. E. McGhee (eds.), The Psychology of Humor. Theoretical Perspectives and Empirical Issues, 3-39. Nueva YorkLondres: Academic Press.

KOESTLER, A. (1964). The Act of Creation. Londres: Hutchinson.

LE GoFf. J. (1999). «La risa en la Edad Media». En E. Burke, A. Gurevich, y J. Le Goff (eds.), El arte de la risa, 40-54. Madrid: Sequitur.

LIPPS, Th. (1923). Los fundamentos de la Estética. Madrid: Daniel Jorro.

LLERA, J. A. (2001). «Poéticas del humor: desde el novecentismo hasta la época contemporánea». Revista de Literatura LXIII, 126, 461-476.

LuDOVICI, (1932). The Secret of Laughter. Londres: Constable Press.

McDougall, W. (1922). «Why do we laugh?». Scribners 71, 359-363.

MILNER, G. B. (1972). «Homo Ridens: Towards a Semiotic Theory of Humour and Laughter». Semiotica 6, 1-30.

Mulkay, M. (1988). On Humour. Its Nature and Its Place in Modern Society. Cambridge: Polity Press.

Palmer, J. (1994). Taking Humour Seriously. Londres-Nueva York: Routledge.

PAZ, O. (1972). «Risa y penitencia». En su obra, Puertas al campo, 155-171. Barcelona: Seix Barral.

Platón (1963). La República. Madrid: Aguilar.

- (1992). Diálogos: Filebo, Timeo, Critias. Ed. y traducción de M.̊ A. Durán y F. Lisi. Madrid: Gredos.

Quintiliano, M. F. (1970). Institutio oratoria, 2 vols. Ed. de M. Winterbottom. Oxford: Oxford University Press.

RAPP, (1951). The Origins of Wit and Humor. Nueva York: Dutton.

RASKIN, V. (1985). Semantic Mechanisms of Humor. Dordrecht-BostonLancaster-Tokyo: D. Reidel Publishing Company.

RICHTER, J. P. (1990). Introducción a la Estética. Madrid: Verbum.

SCHOPENHAUER, A. (1928). «Teoría de la risa». En El mundo como voluntad y representación, vol. I, 168-175. Madrid: Aguilar.

Schulz, T. R. (1970). «The Role of Incongruity and Resolution in Children's Appreciation of Cartoon Humor». Journal of Experimental Child Psychology 13, 456-477.

Suls, J. M. (1972). «A Two-Stage Model for the Appreciation of Jokes and Cartoons: An Information-Processing Analysis». En J. H. Goldstein y P. E. McGhee (eds.), The Psychology of Humor. Theoretical Perspectives and Empirical Issues, ed. cit., 81-100.

Tono [Antonio de Lara Gavilán] (1949). Automentirobiografía. Barcelona: José Janés.

VILAS, S. (1968). El humor y la novela española contemporánea. Madrid: Guadarrama. 